\title{
EL MODO DE PRODUCCIÓN COMUNAL TRIBUTARIO EN LAS SOCIEDADES INCA Y AZTECA
}

\author{
Communal Tax Production Mode in Inca and Azteca Societies
}

\author{
Oscar Panty Neyra ${ }^{1}$
}

\begin{abstract}
RESUMEN
Los gobernantes incas y aztecas personificaban a un Estado Teocrático, no expropiaban tierras a los ayllus y calpullis, pero se erigieron en propietarios simbólicos que distribuian parcelas en usufructo y les extraian tributos.
\end{abstract}

Palabras claves: Estado Teocrático, producción comunal tributario.

\section{ABSTRACT}

The Inca and Aztec rulers personified a theocratic state; they did not expropriate land to the ayllus and calpullis, but were erected as symbolic owners distributing plots in usufruct and extracted tribute from them.

Keywords: Theocratic state, communal production tax.

\section{INTRODUCCIÓN}

\section{La comunidad primitiva y su modo de producción}

La existencia de la humanidad se remonta a más de dos millones de años con la aparición del Homo Hábilis; un ser inteligente que supo manipular objetos de piedra, madera y hueso, y les dio una utilidad en actividades de caza, pesca y recolecta para su sustento, como también para defenderse de las fieras, de las inclemencias del medio y de otros individuos ocasionales rivales en sus áreas de acción. Inicialmente los seres humanos se agrupan formando bandas, luego las gens y los clanes, y después las tribus. Las ban- das (también llamadas hordas) eran grupos de individuos motivados por propósitos y esfuerzos colectivos de caza, recolecta y hasta autodefensa para sobrevivir. Las gens, eran grupos más estables de individuos unidos por vínculos de sangre, lo que ordena su vida social y sexual (se supera al incesto y surge la exogamia), lo que a su vez refuerza la cooperación simple, el trabajo en común y en general el desarrollo de las fuerzas productivas. Varias gens forman los clanes y la unión de éstos dan lugar a la tribu como "forma superior de organización de la comunidad primitiva".

Durante el curso del desarrollo social, los seres humanos forjaron varias

\footnotetext{
${ }^{1}$ Doctor en Ciencias Sociales. Docente Principal de la Facultad de Educación, Comunicaciones y Humanidades de la Universidad Nacional Jorge Basadre Grohmann. Tacna - Perú.

Correoelectrónico:lahistoriacultural@gmail.com
} 
formas de organización desde la sociedad de la comunidad primitiva hasta la sociedad capitalista, pasando por sociedades transicionales. En cada sociedad concreta se ha distinguido la base o estructura económica y la superestructura con sus niveles jurídico-político e ideológico. Para explicar la base económica se ha recurrido a la categoría modo de producción, que también es una realidad objetiva. En la base económica pueden existir varios modos de producción, pero uno es el predominante. El modo de producción es la articulación dialéctica entre las fuerzas productivas (medios de producción y fuerza de trabajo que es el hombre) y las relaciones de producción que son los vínculos que se establecen entre los hombres en el proceso productivo, relación que se basa en la propiedad de los medios de producción. En las sociedades de clases (esclavista, feudal y capitalista), las relaciones se establecen entre los dueños de los medios de producción (fabricas, maquinarias, materia prima) y los trabajadores en el proceso de producción. Tales relaciones de producción determinan la apropiación del excedente, En el régimen capitalista los burgueses se apropian del trabajo excedente mediante la forma de plusvalía. Por el contrario, con el modo de producción de la Comunidad Primitiva, la apropiación era colectiva, porque allí no existía ni la propiedad privada ni la división de la sociedad en clases ni la explotación del hombre por el hombre; los integrantes de las bandas, gens, clanes y tribus usufructuaban en común de las tierras, bosques, ríos, animales diversos, y los instrumentos de producción eran de uso colectivo.

La ley económica fundamental del régimen de la comunidad primitiva era producir los medios indispensables para la existencia de la comunidad con ayuda de instrumentos de producción rudimentarios y a base del trabajo colectivo.

Respecto a la superestructura de la comunidad primitiva (sus concepciones de la vida, la naturaleza, la moral, su organización social y su identidad), no era más que el reflejo de la base, vale decir del conjunto de las relaciones de producción de colaboración. El maestro Aníbal Ponce, en su tantas veces consultado manual de Educación, expresa: "El hombre de las comunidades primitivas tenía, él también, su concepción del mundo, aunque no la hubiese formulado expresamente. Esa concepción del mundo que a nosotros nos parece pueril, reflejaba, por un lado, el ínfimo dominio que el primitivo había alcanzado sobre la naturaleza, y por el otro, la organización económica de su tribu estrechamente vinculada a ese dominio. Puesto que en la comunidad primitiva no se conocían ni rangos ni jerarquías, el primitivo supuso que la naturaleza estaba organizada en igual forma: su religión fue por eso una religión sin dioses. Los primitivos creían, en efecto, en fuerzas difusas, que impregnaban a todo lo existente, de la misma manera como las influencias sociales impregnaban a todos los miembros de la tribu" (Ponce, 1973, p. 174).

Por otra parte, no fue posible la constitución del Estado por la ausencia de las clases sociales y éstas a su vez por la no existencia de la propiedad privada. No obstante, integraron la organización institucional de la sociedad primitiva la matriarca primero, el patriarca y el consejo de ancianos después. Igualmente la organización de las gens y la tribu para enfrentar a otras gens y tribus en lucha por la existencia y ocupación del espacio territorial.

\section{Modos de producción en América autóctona}

No se sabe con exactitud cuándo empezó el poblamiento de América. La 
afirmación más generalizada se remonta a poco más de 40 mil años, cuando América experimentaba los rigores de la glaciación de Wisconsin; entonces se inició el poblamiento continental con la llegada sucesiva de bandas de cazadores, pescadores y recolectores procedentes de Asia, portantes de una cultura típica del paleolítico inferior y medio basada en la confección de pre puntas de proyectil. Atravesaron el estrecho de Bering rumbo a Alaska y se desplazaron progresivamente hacia los actuales territorios de Canadá y Estados Unidos, de cuyos sitios más antiguos se ha fechado en Blue Fish Cave, junto al río Yukon, en 39000 años a.C. En Shriger, al norte de Missouri se localizan útiles de talla unifacial y trabajos en hueso de 43.000 a.C. El Complejo Old Crown, al norte del Yukon, con huesos quebrados y trabajados de mamut y caribú, más que instrumentos de piedra. China Lake con 42350 a.C. Los hallazgos en Isla Santa Rosa, Levi y Lewisville (Texas), fechado en 36,000 a.C.

En Mesoamérica y América Central se ubican El Bosque (Nicaragua) Valsequillo fechado hasta 35000 a.C. Tequixquiac, Tlapacoya o sitios de la Cueva del Diablo y otros lugares mexicanos que documentan el antiguo horizonte de pre-puntas de proyectil.

En América del Sur se ha registrado este mismo nivel cultural con cierta dispersión: Cueva de Pickimachay en su fase de Paccaicasa (Ayacucho Perú), con 22000 años a.C., Rancho Peludo y Manzanillo en Venezuela, Tagua Tagua en Chile y los Toldos en Argentina. Los sitios de Cueva da Pedra Furada (Brasil) de 30200 años a.C. o Monte Verde (Chile) de 31500 años a.C. son indicadores de un poblamiento rápido del continente americano, de tal manera que en el curso de 10,000 años el hombre se desplazó de Alaska a Patagonia. No se descarta otras rutas y procedencia como la de Polinesia.

Esta fue la época temprana de la economía natural primaria de subsistencia, de una plena integración del hombre a la naturaleza en condiciones de dependencia, de la cual tomaba los recursos vitales para su sustento. El mantenimiento de la economía natural por largo tiempo aplazó la definición de un modo de producción. Sobre este aspecto Luis Vitale (1997) expresa: "Si bien es cierto que estos pueblos [se refiere a los recolectores, pescadores y cazadores] no se organizaron para la producción sino para la recolección, no puede desconocerse que hacían un trabajo, especialmente en lo relacionado con la caza mayor. Tenían también, un tipo de organización social para la pesca y la fabricación conjunta de equipos y utensilios" (p. 20).

\section{Modo de producción comunal-MPC-}

Después de varios miles de años de economía natural de subsistencia, las comunidades tribales de América, nómades y trashumantes, frente a la escasez de recursos alimenticios y ante el aumento de la población, pasaron a forjar una economía productora con la domesticación de plantas y animales. Así se impuso el sedentarismo que propició que varios individuos y familias se unieran por vínculos de parentesco, territorio, religión y trabajo, formando comunidades con mayor organización y estabilidad, a las que en la región andina se ha denominado ayllus, y en México calpullis.

Entre las primeras plantas domesticadas en el continente, se destaca: En Perú, el frijol 9000 años a.C.; papa, 8,000 años; camote, de 8,000 a 1,000 años. En la cuenca amazónica, noreste de Brasil, yuca de 7000 a 9000 años. Maíz en México y Perú, 6000 a 8000 años; a.C. Calaba- 
za en México, 8000 años a.C. Por otra parte, los primeros animales que se domesticó en América fueron los camélidos Llama y Alpaca en la región andina, aproximadamente 6000 Años a.C.; el cobayo (cuy) en la región andina, 5000 años a.C.; el pavo en México, 100 años a.C. El perro domesticado desde hace 13500 años a.C., no tiene lugar determinado en el planeta.

La domesticación de plantas y animales, que devino en cultivo y crianza de cierto nivel técnico, determinó la primera gran división social del trabajo, lo que significó la diferenciación de unas comunidades agricultoras de otras ganaderas, instancias en las que se mantuvo el trabajo colectivo y el interés común. En todos los casos, la primera gran división social del trabajo implicó: a) la especialización en el trabajo, consecuentemente el desarrollo de las fuerzas productivas, b) el aumento de la producción y de la productividad, c) el excedente de la producción y el intercambio de este excedente entre las comunidades mediante el trueque.

El desarrollo de la agricultura (plantación, y siembra, cultivo y cosecha, almacenamiento y distribución de productos) demandó el empleo de una serie de instrumentos y utensilios, por lo que se generaron diversos oficios (cestería, cerámica, textilería, metalurgia, etc), que luego se independizaron dando lugar a la segunda gran división social del trabajo: Las artesanías, las cuales aumentaron aún más la producción de bienes, con el excedente para el intercambio.

En el contexto de la primera y segunda división social del trabajo, hace unos 4 mil años a. C. es que se forja el modo de producción comunal, a lo que Luis Vitale se refiere como un modo de producción basado en una relación de producción colectiva donde no existían explotadores ni explotados y en unas fuerzas productivas fundamentales en la agricultura y en instrumentos para el trabajo en la alfarería y procesamiento de los metales. La apropiación del producto era colectiva.

Como ya se ha visto, la existencia de un modo de producción implica la articulación de sus componentes fuerzas productivas y relaciones de producción en el proceso productivo. El modo de producción comunal, en las comunidades agroalfareras de América, fue la expresión de una definida articulación de las fuerzas productivas (instrumentos, recursos naturales y fuerza de trabajo) con las relaciones de producción (trabajo comunal de los ayllus y calpullis, incluyendo trabajo en cada parcela). Vale decir, la articulación de las fuerzas productivas con las relaciones de producción se expresaba en la organización del trabajo común (construcción de canales, riego, roturación de tierras, etc.) para beneficio del conjunto de la comunidad; en la posesión colectiva de la tierra y en la redistribución de parcelas en usufructo a cada unidad doméstica; y, en la apropiación del producto con la redistribución del excedente.

En el modo de producción comunal la unidad doméstica (familia) no era autónoma o autosuficiente, sino que dependía de la comunidad. En el caso del excedente, éste no era apropiado directamente por cada familia, sino por la comunidad que lo destinaba a un fondo común de reserva, lo que a su vez sería distribuido a los miembros de la comunidad en tiempos de escasez, o en obras de interés común, o en actos ceremoniales. De acuerdo a Luis Vitale, el excedente de la 'producción comunal, permitió una división del trabajo más acentuada; algunos miembros de los ayllus y calpullis dedicaron parte de su tiempo a la elaboración de productos no 
necesariamente destinados a la alimentación, lo que derivó en la generación de sectores especializados en metalurgia, alfarería, tejidos, cestería, madera, cuero, plumas, entre otros artesanos. Tales sectores, no obstante su especialización, se mantenían e integrados a la comunidad; su trabajo formaba parte del modo de producción comunal; los objetos que fabricaban estaban al servicio del ayllu o del calpulli, con lo que contribuyeron a mejorar las herramientas e impulsar el desarrollo de las fuerzas productivas.

Durante la época del modo de producción comunal los miembros de cada unidad familiar practicaron la ayuda mutua en el trabajo (ayni, minka), una auténtica reciprocidad $\mathrm{v}$ con un elevado nivel de identidad comunitaria. Igualmente se practicó la redistribución del excedente de la producción no por la gracia de una autoridad o gobernante comprensivo, sino por "el resultado de un acuerdo conjunto e igualitario de los miembros de los ayllus y calpullis. La reciprocidad y la redistribución se verán afectadas después, cuando se impone el tributo con las elites que se encumbran en las comunidades y surgen los señoríos y los estados regionales.

\section{El modo de producción comunal tribu- tario-MPC-T.}

\section{La transición del MPC al MPC-T}

La dinámica del modo de producción comunal (desarrollo de las fuerzas productivas, aumento de la producción y productividad, control y redistribución del excedente de la producción social, diferenciación del trabajo intelectual del manual), llevó a generar las primeras estructuras de poder: jeraquías y rangos de jefes y shamanes. La autoridad de los jefes y shamanes se impuso sobre la comunidad aparentando capacidades superiores, sobrehumanas, que utilizaban a favor del bien común.

El jefe centralizó el excedente de la comunidad y lo destinó para sustentar el trabajo de grandes obras en bien de la comunidad, tales como construcción de canales, represas, fomento de nuevas áreas agrícolas. Pero también el jefe utilizó el excedente de la comunidad para el intercambio con otras comunidades, dando lugar al reparto de los bienes obtenidos a sus seguidores. A todas luces, esta actividad resultaba grata para la comunidad en tanto aparecía como un servicio del jefe. La comunidad entregaba el excedente social al jefe y esperaba de él su devolución en un equivalente. "Los jefes locales comenzaron a desbordar su comunidad gentilicia, procurando unir tribus y aldeas, ya sea por motivaciones económicas como religiosas y de política intertribal. El objetivo era llegar a constituir un poder central que consolidara la unidad de las tribus y permitiera un mayor control de la redistribución de excedentes. El principal intento, en este sentido, fue el de los mayas del segundo imperio (900 a 1500), al constituir la Liga Mayapán (Vitale, 1983, p. 91).

Los shamanes (brujos, hechiceros, magos, adivinos), fueron personajes infaltables en las comunidades primitivas de cazadores y recolectores. Se les atribuyó la capacidad de curación de males, comunicación con los espíritus, modificación de situaciones climáticas y determinación de zonas de caza favorables. Mediante actos rituales prepararon el estado anímico de los cazadores para una faena exitosa. Sus conocimientos de la psicología humana unidos a sus saberes sobre las propiedades de las plantas medicinales, además de sus inquietudes por asociar el curso de los astros con el destino de los seres humanos, los convirtieron en los iniciadores de la separación del trabajo intelectual del manual. Los 
shamanes avanzaron de los rituales mágicos a la elaboración de la ideología religiosa. Se estima que hacia el año 200 a.C. los shamanes aparecen conformando el estrato social de los sacerdotes.

De esta manera, sobre la base del modo de producción comunal, las comunidades agroalfareras mantuvieron la propiedad colectiva de la tierra, pero se dio el inició de las desigualdades sociales con la centralización del excedente de la producción social y su redistribución por intervención de las elites emergentes de jefes, shamanes y sus colaboradores. "Se dio así-confirma Vitale- una situación contradictoria en que la comunidad daba voluntariamente curso a la centralización del excedente, sin tomar conciencia de que a la postre ese paso sentaría las bases de la dominación. (Vitale, 1983 , p. 89). La entrega voluntaria del excedente de la producción social, devino en entrega obligada bajo la modalidad de tributo. El modo de producción comunal devino en modo de producción comunal tributario. Las formaciones sociales Chavín (1000 a.C.), Paracas (700 a.C.), Moche (100 d.C.), Tiwanaku (200 a. C.) y Wari (600 d. C.) en la región andina; Olmecas (1200 a. C.), Toltecas (800 d.C.) y Mayas (300 d.C.) en Mesoamérica, tuvieron por base económica el modo de producción comunal tributario; tales sociedades prepararon las condiciones objetivas para el surgimiento de las formaciones sociales Inca y Azteca.

El modo de producción comunal-tributario en las formaciones sociales inca y azteca

Cuando los españoles llegan a las islas del Mar Caribe con el expedicionario Cristóbal Colón, año 1492, se encuentran con grupos humanos de incipiente nivel cultural, entre cazadores y horticultores, a los cuales doblegan fácilmente, y hasta los exterminan en tanto reaccionan a su presencia invasora. En el continente americano existían dos formaciones sociales de mayor desarrollo cultural: Azteca en Mesoamérica e Inca en la región centroandina, a cuya conquista enfilaron posteriormente los invasores españoles.

El origen de los aztecas (llamados también méxicas), se ubica entre los grupos hablantes del náhuatl del norte del actual México. Su migración hacia el altiplano central ocurrió entre los siglos XII y XIV. En su trayecto tuvieron que enfrentar a diversos pueblos como los tepanecas y culhuacas, hasta que se posicionaron de un islote al poniente del lago Texcoco, fundando Tenochtitlan el año 1325. Se estima que a partir de 1430 , en alianza con los altepetl de Texcoco y Tlacopan, los aztecas derrotaron a los tepanecas e impusieron su dominio en la región sobre la base del tributo, siendo sus gobernantes más destacados Moctezuma I (1440-1475) y Moctezuma II o Xocoyotzin (1503-1520).

Según la tradición los incas liderados por Manco Capac fundaron el Cusco hacia el año 1200, permaneciendo como un reino local hasta que Pachacutec (1438-1471), luego de la guerra victoriosa contra los chancas, emprendió un proceso de expansión territorial, el mismo que durante el reinado de Huayna Capac (1493-1525) llegó por el norte hasta Pasto en Colombia y por el sur hasta el rio Maule en Chile. Los Incas respetaron los ayllus con sus tierras, pero en algunos lugares controlaron parte de esas tierras con la introducción de los mitimaes. Como se sabe los mitimaes eran grupos de familias que se desplazaban por orden del Inca para su desempeño en funciones de control de territorios incorporados, colonización o reasentamiento humano.

Tanto los incas como los aztecas fueron los continuadores de los avances de las culturas precedentes en materia 
de agricultura, riego artificial, minería, metalurgia y artesanías. Incas y aztecas organizaron sus sociedades sobre la base de la producción comunal y la tributación al Estado controlado por una élite que, además, se apropiaba de una parte del excedente social.

Se ha discutido bastante sobre el modo de producción que primó en las formaciones sociales Inca y Azteca, de lo cual se ha distinguido modo de producción comunista o comunista agrario (planteado por Luis e. Valcarcel, César Antonio Ugarte y Pío Alvarado, entre otros); esclavista-patriarcal (Carlos Núñez Anavitarte); semiesclavista y semifeudal (Gustavo Valcarcel); modo de producción asiático (enunciado por Marx y sostenido por Maurice Godelier, Mercedes Oliva, Salomón Nahmad y Agustín Barcelli); por último, modo de producción comunaltributario (sustentado por Luis Vitale).

Se cuestiona diametralmente el planteamiento de modo de producción comunista o comunista agrario para las sociedades inca y azteca, puesto que en su base económica se desarrollaba una pugna entre las fuerzas productivas que defendían la propiedad colectiva de la tierra y la cultivaba, y la minoría privilegiada que exigía la entrega de tributo en bienes y trabajo contando con los mecanismos de un aparato estatal. No se puede concebir un comunismo agrario donde hay desigualdades sociales y donde hay Estado. El comunismo significa igualdad en las relaciones entre los componentes del colectivo humano; distribución igualitaria de los productos; reciprocidad efectiva sin intervención ni presencia de entidades coactivas como el Estado, lo que no ocurrió en sociedades avanzadas como la Inca y Azteca.

El modo de producción esclavistapatriarcal, se define por la existencia de una clase gran propietaria del trabajador y de los instrumentos de producción. $\mathrm{Ni}$ entre los incas ni entre los aztecas hubo un régimen de esclavitud en el sentido estricto del término. Ni los yanas ni los mayeques fueron esclavos. Los pinas durante los incas y los tlatlacotin durante los aztecas fueron rudimentos de esclavitud que no define el carácter de tales sociedades Obviamente que se reconoce prestaciones forzosas de servicios en las obras de regadío, cultivos y las construcciones monumentales.

Igualmente se cuestiona la afirmación del modo de producción feudal o semifeudal en las sociedades inca y azteca. El modo de producción feudal que si se habrá de observar en todo su vigor en el espacio-tiempo europeo, se basaba en el trabajo del siervo al servicio del señor dueño de la propiedad privada de la tierra, vale decir el tributo del siervo al señor feudal bajo la forma de trabajo. Durante el régimen de los incas y aztecas el tributo a la élite que personificaba al Estado lo realizaba no el individuo de manera personal, sino la comunidad que aún mantenía la posesión comunal de la tierra. En ambos casos la tributación era expresión de servidumbre, pero no toda servidumbre es feudal. Las comunidades incas y aztecas conservaron sus tierras, su modo comunal de producir y no actuaron en la condición de vasallos como los individuos de la época feudal europea.

En cuanto al modo de producción asiático, diferenciado por Marx en su borrador Formas que preceden a la producción capitalista (que se abstuvo de publicarlo porque consideró que requería de mayor tratamiento), fue estudiado en las sociedades orientales como un modo de transición de las sociedades preclasistas a las sociedades clasistas. Marx destaca la existencia de "pequeñas entidades comunitarias" "autosuficientes" que complementan la agricultura con la 
manufactura, sobre las cuales se impone una "unidad omnicomprensiva" que les demanda la entrega del plusproducto como tributo, por lo que aparece como el propietario superior que a su vez asume la programación de obras públicas para garantizar la generación del plusproducto y su entrega. Al respecto, Marx escribe: "En la mayor parte de las formas fundamentales asiáticas la unidad omnicomprensiva, que está por encima de todas estas pequeñas entidades comunitarias, aparece como el propietario superior (...). El plusproducto -que además se va determinando legalmente como consecuencia de la apropiación efectiva a través del trabajo- pertenece entonces de por sí a esta unidad suprema. Por lo tanto, en medio del despotismo oriental $\mathrm{y}$ de la carencia de propiedad que parece existir jurídicamente en él, existe de hecho, como fundamento, esta propiedad comunitaria o tribal, producto sobre todo de una combinación de manufactura y agricultura dentro de la pequeña comunidad, que de ese modo se vuelve enteramente autosuficiente y contiene en sí misma todas las condiciones de la reproducción y la plus producción. Una parte de su plus trabajo pertenece a la colectividad superior, que en última instancia existe como persona, y este plus trabajo se hace efectivo tanto en tributo como en el trabajo común destinado a exaltar a la unidad, en parte el déspota real, en parte a la entidad tribal imaginada, el dios (...). El carácter colectivo del trabajo mismo, lo cual puede constituir un sistema formalizado como en México, en especial Perú, entre los antiguos celtas, algunas tribus de la India (Marx, 2009, p. 69-70).

Luis Vitale que estudió acuciosamente el pasado americano, admite que un modo de producción similar al asiático fue el que impulsó al desarrollo de las culturas Inca y Azteca, pero repara en que el término "asiático" es de orden geográfico y no corresponde para designar "relaciones de producción", por lo que supone que Marx debió de haberlo utilizado "provisoriamente". Vitale sostiene: "Las formaciones inca y azteca se basaban en un modo de producción que nos hemos permitido denominar comunal-tributario. La élite dominante de esas sociedades usufructuó del modo de producción comunal de las culturas sometidas, imponiéndoles un tributo y apropiándose de parte del excedente o plusproducto, es decir, apropiándose de una parte de la fuerza de trabajo de las comunidades" (Vitale, 1983, p. 68).

Vitale considera que la caracterización de modo de producción comunaltributario para las culturas inca y azteca es más precisa que el término modo de producción "asiático". En este sentido sostiene: "Por comunal entendemos la actividad conjunta que efectuaban las unidades domésticas -ayllus y altépetles- dentro de la tribu. Estos núcleos familiares trabajaban las parcelas que en usufructo les había repartido la comunidad, pero realizaban tareas comunes de manera colectiva y ayudaban a otras familias a través de un sistema cooperativo o de "minga". Asimismo agrega: "Aunque el Estado había sometido a la comunidad-base, en las formaciones sociales inca y azteca no se había cortado el cordón umbilical con la posesión colectiva de la tierra y la producción comunal. No obstante, se generaron desigualdades sociales, acentuándose las contradicciones entre campesinos y artesanos y entre ambos y la élite dominante -militares, sacerdotes, funcionarios estatales-, que vivía del trabajo de las comunidades base (Vitale, 1983, p. 6869).

A diferencia del mexicano Roger Bartra que caracteriza al modo de producción azteca como modo de produc- 
ción tributario, Vitale sostiene que no es suficiente afirmar que tal pueblo estaba sometido a tributación, sino señalar cuál era su forma de producir y bajo qué relaciones de producción. El tributo en trabajo-que es parte del área productiva-es una relación social que contribuye a definir un modo de producción; pero es insuficiente para caracterizar el de los incas y aztecas, porque -sin dejar de lado la tributación- lo fundamental era la producción de sus comunidades de base. En efecto, el tributo, tanto en trabajo como en especie, obligaba a que ayllus $\mathrm{y}$ calpullis generaran un excedente económico bajo relaciones de producción comunal, lo que determina que se articulen los calificativos tributarios y dando lugar a la categoría modo de producción tributario-comunal.

\section{CONCLUSIONES}

A la llegada de los invasores ibéricos al continente americano, imperaba en las formaciones sociales Inca y Azteca el modo de producción comunal tributario. Las comunidades agrarias de base (ayllus y calpullis) se esforzaban por producir un excedente -más allá de la satisfacción de sus necesidades vitales-, porque debían cumplir con el tributo impuesto por la élite dominante.

Con el modo de producción comunal tributario se proyectan las clases sociales básicas: La elite dominante y la comunidad de base. La elite dominante no cultiva la tierra, pero se mantiene con el tributo en bienes y trabajo de las comunidades sometidas.

Los gobernantes inca y azteca que personificaban al Estado teocrático, no expropiaron las tierras en posesión de la comunidad, pero se erigieron como los propietarios simbólicos que repartían graciosamente las parcelas en usufructuo.

\section{REFERENCIAS BIBLIOGRÁFICAS}

Espinoza, W. (1985). Los modos de producción en el imperio de los Incas. Lima, Perú: Recopilación. Amaru Editores.

Marx, C. (2009). Formaciones económicas pre capitalistas. México D.F., México:Siglo XXI Editores.

Ponce, A. (1973). Educación y lucha de clases. Buenos Aires, Argentina: Ed.el viento en el mundo.

Vitale, L. (1997). Historia Social Comparada de los pueblos de América Latina. Santiago, Chile: Instituto de Investigación de Movimientos Sociales "Pedro Vuskovic" y Talleres de Impresos Atalí.

Vitale, L. (1983). Génesis y desarrollo del modo de producción comunal - Tributario de las formaciones sociales inca y azteca. Boletín Americanista, Universidad de Barcelona. 